\title{
Social Media and Its Impact on Small Projects: An Empirical Study in the State of Kuwait
}

\author{
Khaled Mohammad Khalaf Mohammad Al-Dreban ${ }^{1}$ \\ ${ }^{1} \mathrm{Ph}$.D. student in Business administration on the world Islamic sciences and education university, Kuwait \\ Correspondence: Khaled Mohammad Khalaf Mohammad Al-Dreban, Business administration on the world \\ Islamic sciences and education university, Kuwait.
}

Received: August 25, 2020

Accepted: September 14, 2020

Online Published: September 23, 2020

doi:10.5539/ibr.v13n10p95

URL: https://doi.org/10.5539/ibr.v13n10p95

\begin{abstract}
The current study aimed at identifying the impact of social media on the small business in the state of Kuwait. The study population consisted of all workers in small business, and they were (720) workers. A simple random sample consisting of (300) workers was selected and (208) were retrieved. The study was distributed according to demographic variables (gender, educational qualification, experience). The study concluded that there is a statistically significant impact of social media on promoting the products of small business in the State of Kuwait through a simple linear regression test. This result indicates that social media influences the positive and noticeable method of promoting small business products.

The current study has reached a number of recommendations, the most important of which are:

The importance of small and medium companies adopting social media in their activities, especially in marketing and promotion activities, and the and the need to form working groups specialized in social media in these projects to improve the effectiveness of promoting their products, and finally, inviting researchers to study social media and their impact on other marketing activities such as pricing, selling and marketing confidence, customer loyalty and satisfaction.
\end{abstract}

Keywords: social media, small projects small projects, Kuwait

\section{Introduction}

Social media has demonstrated, over a decade, an growing involvement in the everyday life of individuals and commercial activities, and in the engagement on the promotion of commodities for small projects in the State of Kuwait, and we would not be far from the facts if we conclude that social media has become a fundamental requirement in our everyday personal life for the promotion of commodities for small projects in the State of Kuwait.

Social networking does not focus exclusively on merely submitting details to and inspiring the proponents of small ventures of products in the State of Kuwait and promoting them in magazines, TV and films. Online networking offers unparalleled incentives for tiny ventures to transmit their brand content directly to their intended consumers, and plays an important role in influencing their purchasing behaviors, and small projects have begun to adopt them as a marketing tool with the strengths, capabilities and impacts that make them benefit from them, and are working to develop a way in which they have carried out their work accordingly.

The promotion of small projects is not immune to the services provided by social media, but rather has a large share of interaction and attracts its fans and customers, as customers publish information, photos and videos directly through their electronic devices and clarify their experiences and awareness of the food, types and quality of services provided in the restaurant. This adds to the creation of a conceptual picture similar to truth, because this association is attributed to personal knowledge and propaganda.

This research focuses on the topic of social media in order to define it across its key aspects (conversations, communities, engagement, collaboration, relations) and to assess its effect on the promotion of goods for small projects in the State of Kuwait.

\section{Problem of the Study}

The problem of the study in the urgent need for small projects in the State of Kuwait to expose preferences for 
the promotion of goods and their specific measurements, and to recognize the factors influencing them, is that of improving the marketing mechanism in line with these preferences, This is expressed in the accomplishment of the required social networking goals, since it is one of the new marketing strategies that ensures contact, meaningful and consistent engagement with consumers and is an valuable source of knowledge.

\section{Study Questions}

The study is represented by the following main question:

"What is the impact of social media Facebook, Instagram (conversations, groups, participation, partnership, relations) in achieving the promotion of commodities for small projects in the State of Kuwait?"

The following sub-questions branch out of this main question:

What is the extent of social media conversations in on promotion of commodities for small projects in the State of Kuwait?

What is the extent of the practice of social media participation in on promotion of commodities for small projects in the State of Kuwait?

What is the extent of social media groups' practice in on promotion of commodities for small projects in the State of Kuwait?

What is the extent of social relations relationships on promotion of commodities for small projects in the State of Kuwait?

\section{Importance of the Study}

The importance of this study comes from:

1. Trying to concentrate on the importance of social networking and its effect on the promotion of goods for small ventures in the State of Kuwait to staff and keeping abreast of all new trends in the field of social media promotion.

2. The researchers recommended that this study will motivate many researchers to study social media topics and to promote commodities for small-scale projects in the State of Kuwait in various economic institutions and sectors.

\section{Objectives of the Study}

The aim of this study is: to identify the impact of social media (conversations, groups, participation, partnership, relations) on the promotion of commodities for small projects in the State of Kuwait.

1. Contribute to the development of a theoretical and conceptual framework for study

2. Make useful recommendations in the field of social media and promotion of commodities for small projects in the State of Kuwait

\section{Hypothesis of the Study}

To achieve the objectives of the research by studying the impact of the dimensions of social media on promotion of commodities for small projects in the State of Kuwait, it has been relied on a set of hypotheses, as follows:

Ho1: "There is no statistically significant effect at the level of significance $(\alpha \leq 0.05)$ the dimensions of social media (conversations, groups, participation, partnership, relations) in promotion of commodities for small projects in the State of Kuwait

Ho1-1: "There is no statistically significant effect at the level of significance $(\alpha \leq 0.05)$ of the talks in promotion of commodities for small projects in the State of Kuwait

H01-2: "There is no statistically significant effect at the level of significance $(\alpha \leq 0.05)$ to participate in promotion of commodities for small projects in the State of Kuwait

H01-3: "There is no statistically significant effect at the level of significance $(\alpha \leq 0.05)$ for the groups on promotion of commodities for small projects in the State of Kuwait

H01-4: "There is no statistically significant effect at the level of significance $(\boldsymbol{\alpha} \leq 0.05)$ of the relationships in on promotion of commodities for small projects in the State of Kuwait.

Ho2: "There is no statistically significant effect at a significance level of $(\alpha \leq 0.05)$ the dimensions of social media sites (conversations, participation, groups, relationships) in promoting the products of small enterprises in the State of Kuwait by different gender. 
Ho3: "There is no statistically significant effect at level of significance $(\alpha \leq 0.05)$ dimensions of social media sites (conversations, participation, groups, relationships) in promoting the products of small enterprises in the State of Kuwait according to scientific qualification."

\section{Study Model}

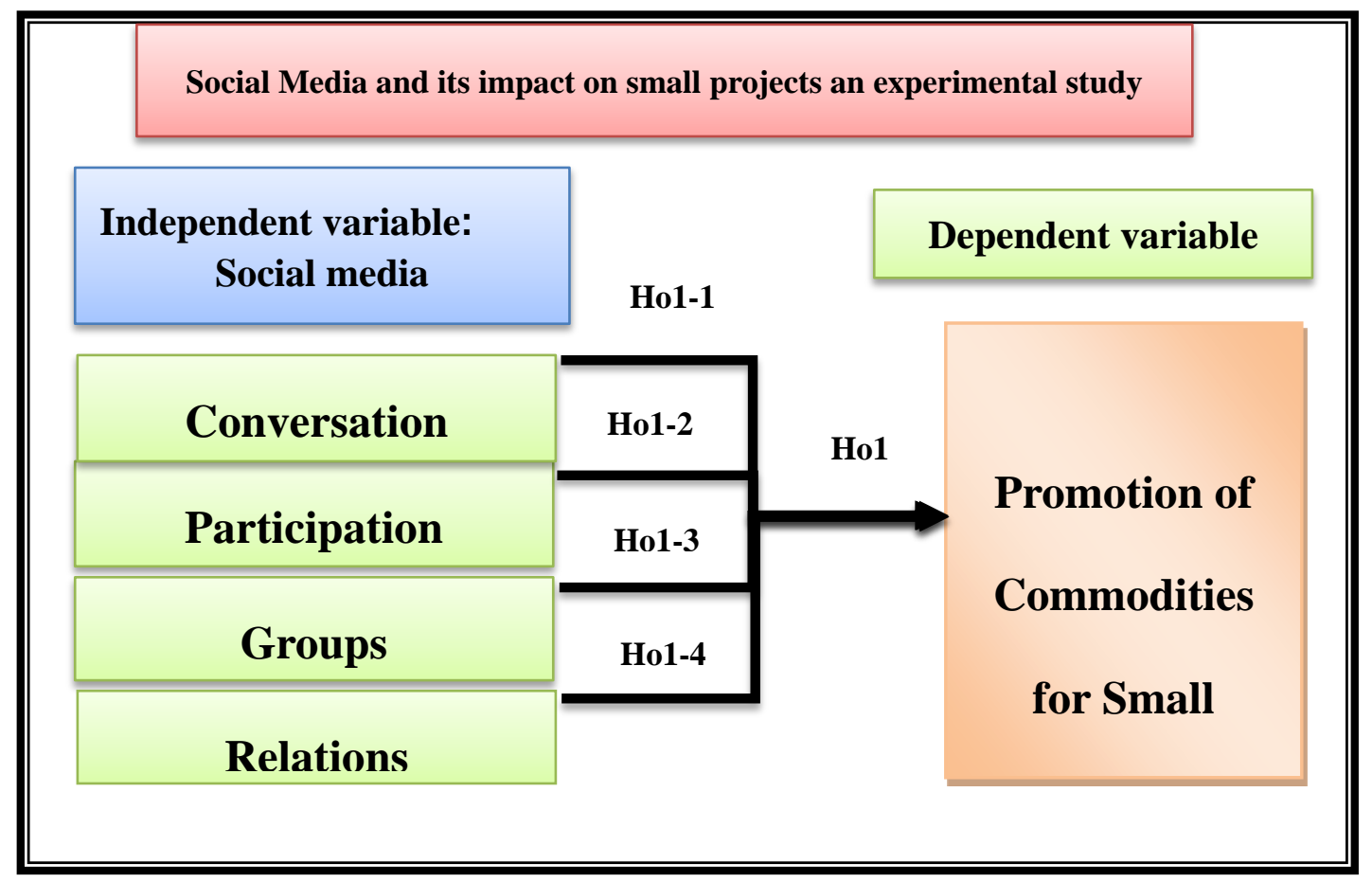

Figure 1. Model of Study

\section{Literature Review}

Social media: Recent years have undergone enormous changes that have been significant marketing obstacles since the dawn of the new millennium, possibly the most important of which are technical innovations, whether at the level of economies, the skills of manufacturing or the means of communicating with consumers.

The emergence of the Internet is known to be one of the most significant technical developments in the modern period, since by definition it does not demand a large expense and makes its users-from all areas of the world-to have convenient access to it, making it a strong forum for businesses to interact easily with their consumers.

With the emergence of the direct contact transition and the facility's relationship with the client directly, the facility and the consumer have been face-to - face, working together by coordinated relationship by digital communications devices that far outweigh the capability of the single vendor in time and travel, and means of interpretation and clarity.

In 2016 Qabo'u was conduct a study titled the impact of social media networks usage on customers' knowledge, customers' acquisition, customers' retention, and case study - Marka VIP Company. 100 questionnaires has been distributed, 98 questionnaire was returned, and after analysis it statically, the result has shown that there is an impact on social network usage (Facebook, Twitter, YouTube) on customers' knowledge, and there was a positive impact of using Facebook on customer acquisition, and that the company's use of social networks (Facebook, Twitter, YouTube) helped the company to retain the current customers from the point of view of the study sample, as the company builds a strong relationship based on trust between it and its customers, and social media networks helped target new customers of the company from different categories.

The concept of social media: The meanings of social networking ranged due to the various principles correlated with them, and the following is a summary of a few of the more popular of such descriptions: describe them (Kaplan \& Haenlein, 2010, 60): as an Internet utility, it helps individuals to do many activities, such as establishing connections with other users, use these means to entertain through the games available to them, and 
social communication with others, and also allows the creation and exchange of user-created content, and the exchange of information, about similar interests, and discuss their favorite topics.

Social media is the concept sometimes used to apply to modern types of communication including collaborative interaction. The development of the media is often divided into two different ages, the broadcast age and the interactive age. Throughout the broadcast age, the media were almost entirely clustered where one entity — such as a radio or television station - was based. Newspaper service, or video development studio - distributed communications to a number of men. Media feedback was often indirect, delayed, and impersonal. Mediated contact between people normally existed on a much smaller basis, generally through personal notes, phone calls, or often on a much larger scale, by means such as photocopied family newsletters. Manning, J. (2014.)

Looking at these and other definitions, it is possible to define the following main elements on which the integrated definition of social media is based (Beshmaf, 2016) (Obaidat and Al-Ghadeer, 2011):

- It has various and different means in its designs.

- It introduces itself to all the people who are interested as networking sites.

- It provides its services via electronic communications.

- Methods of communication through it include text messages, instant and indirect chats, video calling, and comments.

- It allows the exchange of information, opinions, and ideas among interested individuals.

It can therefore be described as "various and diverse electronic platforms, with their structures, modes and services, on the Internet that offer users the opportunity to dialog and exchange information, opinions and ideas through personal files, photo albums, video sharing and chat rooms."

The most popular social media:

(Facebook): Facebook is a social networking website launched in February 2004 and is privately operated by Facebook, Inc. (Facebook, 2004). Facebook was created by Mark Zuckerberg and others while he was a Harvard undergraduate, and when the web was first released, it was open exclusively to students at Harvard. Later, the privilege was extended to high school students and later to those 13 years of age or older (Boyd, 2007).

Facebook provides several benefits for social networking users, allowing participants to submit and receive updates, participate in online discussions, follow up on other people's content, create accounts, and build communities. Facebook is perhaps one of the most commonly used social platforms because of its ease of usage and its other benefits. (Hamdan, 2016). (Dunbar, Arnaboldi and Passarella, 2015, 42).

(Twitter): 2006 was Twitter's year of existence while Facebook started to open its doors to all. Twitter gained a lot of popularity first because it offered more options like micro blogging, and second because some celebrities used it (Jasra, 2010; Tweeternet.com, 2010).

There are lots of benefits of Twitter not just on the personal level, but also on the corporate side, because it provides the ability to reveal any of the activities and unique milestones, it has become a trend for it as a medium of marketing and advertisement for other company organizations. (29, 2013 Ezumah).

(Linked In): This network was developed in (2003) and is known to be one of the social and technical means, since this network focuses on the expertise and competencies that individuals possess, in addition to their job and knowledge, since compared to many of the means that rely on Personal information for consumers, and this network enables individuals to pursue jobs;

Distinguished and skilled people, by their interaction with companies and businesses, to establish partnerships with them and to improve their technological and managerial expertise and capabilities. It is achieved by showing a CV that typically contains the degree of qualifications and prior experience of people, on-site, and exchanging it for everyone to see (27, Thelwall, 2009).

(Instagram): This is a social network for the sharing of images and videos, released in October (2010), and enables users to take pictures and videos, and this network enables users to edit these photographs and videos, make changes to them, and post them with friends and fans, and originally Instagram was enabled on IPhone, iPad, and iPod Touch.

In April (2012), the Instagram network extended support to the Android app, when the network was accessible on the screens of mobile phone apps such as Samsung smartphones, which contributed to expanded usage and sharing by consumers. (54, by Miller, by 2015). 
The basic components of social media: There are several key components of social networking, called social network modules or practical parts, since these studies have emphasized the significance of the following elements since essential components of social networking, which are as follows (Al-Dibsi and Chefs, 2013):

- (Conversation): Represents the degree to which users connect and engage with each other in the context of text messaging on specific topics, where one of the users starts the discussion by inserting relevant material that allows other users to respond to it, and discussions are conducted via social networking in an accessible and transparent manner, encouraging users to debate, dialog and share an opinion; because this interaction may take place between two users and involve multiple formats, such as instant messaging, oral communications and video chatting, and there could be millions of people observing and engaging with these discussions. (Henderson \& Bowley, 2010: 240).

- (Sharing): Sharing is a very critical part of social networking. Users may download, transmit, share and exchange information between them by participation. The material that is exchanged is a crucial factor that mediates the interaction between users. That is the basis for their interconnectedness and interactions on the Internet, because exchanging knowledge with others is a collective activity of two forms of determinants. What information should be shared? With whom is this information shared? (255 Sohn, 2009,).

Users share the content defined by their details, photos or video files, while users who obtain the content will be involved in the content and may share it again with other users. (Lee \& Ma, 2012: 332).

(228 Osatuyi, 2013) indicates that users continue to distribute and republish content (information, images, videos) if the material is accurate, secure, reliable and can benefit from it. Sources of participation cover Twitter posts, messages, consumer feedback and comments on Facebook accounts.

As a consequence, the perceived quality and user expectations of content (information, photos, and videos) decide the degree to which users choose to share this content with other users through social media.

- (Groups): Social media groups refer to associations that people may enter or build in the virtual world through social media platforms, and these groups may be either major groups, defined by inclusiveness and interacting with a general theme, or subgroups, associated with subjects that fall within and subdivide the main group. (Fulcher, 2014, n. 10).

Users build communities for the purpose of sharing and engaging with other users, where material (information, images and videos) is shared on preferences, issues and popular opinions, or where people with similar interests and opinions and topics of mutual interest are included. [165, Tang \& Liu, 2010].

- (Relationship): It expresses the ability of users to connect with other users and to make friends with each other within the social media environment, where users have the freedom to communicate with and offer to engage with other users and to make friends with them, especially where there are personal relationships or shared interests. Many social networking users often give recommendations about how to communicate with other users based on their previous choices.

Social media connections apply to the manner in which users respond to each other in the virtual world with the purpose of social networking and content sharing, and thus the relationships provided by social media sites decide whether and how the exchange of information between users may be official and coordinated, as in the Facebook network, or unofficial and unorganized; as is the case in Twitter network (103Trainor etal., 2014,)

Promoting commodities for small projects: The ideals of promotion, even though they are the same in both of the service and industrial development industries, so that the procedure in the service sector cannot be the same as that practiced by the manufacturing system.

The selling of services poses a variety of challenges relative to consumer products, and this is attributed to the attributes of services, in particular intangible properties. Promotion is described as "coordination between the efforts of the seller to create knowledge sources and to promote a product or service or to embrace a particular idea. "It is also known as "that part of the communication that aims to inform and remind the consumer of the good or service produced by the company and influences it for its acceptance and use." (George et Berry).

Emphasis must be put on the advertising to be successful in conjunction with the spoken word and to guarantee what is feasible, as the commitment will suit the quality of the bid. Giving specific icons, i.e. representation of a business, either by logos or in a visible way Consistency to persuade prospective clients of the authenticity of the deal (El Sayed, Abdel Aal, 2009).

Relationship of contact with advertising: advertising is one of the forms of communication which is called marketing communications, although many typical poor people have not understood that the different 
promotional messaging strategies must be organized between them in order to establish successful contact, and thus the concept of integrated marketing communications has emerged; particularly in American companies Integrated marketing communications in the eighties of the last century mean, on the one hand, the integration between the different promotional elements and, on the other, the various other marketing activities related to the clients of the institution.

A working group of the American Association of Media Agencies has established or identified the meaning of integrated marketing communications, which reads, "It is a marketing strategy planning term that focuses on the added benefit of a holistic strategy that takes into account the importance of the strategic position of different communication fields, such as advertisement and direct marketing; sales promotion, public relations, mixing and connecting between these fields are expected to have a transparent, reliable and strong effect on communications "(Al-Nsour, Al-Manasrah, and Ziadat, 2016).

\section{Study Methodology}

This study followed the descriptive and analytical approach where the researcher developed a questionnaire that reflects the study variables to measure the impact of social media networking in its dimensions (conversations, groups, participation, relationships) on promoting the products of small enterprises in the State of Kuwait, where the study community is one of the companies that own small projects. The number of workers in these companies is (720) employees. The study sample was selected through a simple random sample after referring to the statistical tables according to (Sekaran and Bougie, 2016). The optimal number of the sample size was (251) questionnaires, and (300) questionnaires were distributed. On the study sample, (208) questionnaires valid for statistical analysis were retrieved with a recovery rate of $(69.3 \%)$. The sample members were distributed according to demographic variables according to Table (1), which shows the distribution of the study sample according to demographic variables (gender, academic qualification, experience)

\section{Study Population and Sample}

The research population consists of all jobs in small ventures in the State of Kuwait, with a minimum of (720) staff. A basic random sampling of (250) employee has been accepted. The research team consists of staff (Director, Deputy Director, Marketers, and Administration).

Table 1. the demographic characteristics of the study sample

\begin{tabular}{|l|l|l|l|}
\hline Variable & Frequency & percentage \\
\hline \multirow{3}{*}{ Gender } & Male & 163 & $78.4 \%$ \\
\cline { 2 - 4 } & Female & 45 & $21.6 \%$ \\
\hline \multirow{3}{*}{ Qualification } & Secondary and lower & 53 & $25.5 \%$ \\
\cline { 2 - 4 } & Bachelor's degree & 121 & $58.2 \%$ \\
\cline { 2 - 4 } & Postgraduate & 34 & $16.3 \%$ \\
\hline \multirow{3}{*}{ Years of Experience } & Lower than 5 years & 144 & $69.2 \%$ \\
\cline { 2 - 4 } & From 5 to 10 years & 47 & $22.6 \%$ \\
\cline { 2 - 4 } & More than 10 years & 17 & $8.2 \%$ \\
\hline Total & & 208 & $\% 100$ \\
\hline
\end{tabular}

By referring to Table (1), which shows the demographic characteristics, it becomes clear that most of the sample is males with a number of 163 individuals and a percentage of $78.4 \%$. As for females, their number reached 45 individuals with a percentage of $21.6 \%$. As for the distribution of the study sample according to academic qualifications, most of the respondents were holders of a degree. Bachelor's degree with 121, with a percentage of $58.2 \%$, and then secondary or less with 53 individuals, at a percentage of $25.5 \%$. The number of those with higher degrees was 34 individuals, with a percentage of $16.3 \%$. As for the distribution of the study sample according to years of experience, most workers with years of experience less than 5 years were 144 With a percentage of $69.2 \%$, the number of workers whose experience ranges from 5-10 years was 47 individuals, at a percentage of $22.6 \%$. Finally, the number of workers with experience of more than 10 years was 17 individuals, at a percentage of $8.2 \%$

\section{Study Tool}

The study tool was developed by reviewing the literature related to the subject of the study, where studies were relied upon to develop the study tool and then translate the prepared questionnaire into Arabic so that the respondent could better understand the paragraph and this was confirmed by (Saunders et al., 2016) The five-point Likert scale was relied upon, which is graded from (1), which represents (strongly disagrees) and (5), 
which represents (strongly agree).

\section{Validity and Reliability of the Study Tool}

Before testing the hypotheses of the study, the researcher tested the validity of the questionnaire through the exploratory factor analysis test as shown in Table (2), where the statistically acceptable threshold is considered if the factor loading were greater than (0.70) (Hair et al., 2010; Hair et al. The value of the Kaiser-Mayer-Olkin KMO test for the adequacy of the sample is greater than (0.50), and the stability of the questionnaire was also confirmed by the values of the Cronbach Alpha coefficient, where the values of the Cronbach Alpha coefficient are accepted if they are (0.60) or greater according to (Sekaran and Bougie, 2016) Table (1) shows these values, where all the values of the load coefficients were greater than (0.70) and the values of the KMO test were greater than $(0.50)$ and therefore the sample size was appropriate and all the values of the Cronbach Alpha coefficient were greater than $(0.60)$. Therefore, the stability of the resolution is achieved and thus the validity of the data can be considered for statistical analysis.

\begin{tabular}{|c|c|c|c|c|}
\hline Variable & Paragraph Code & Factor loading & KMO test & $\begin{array}{ll}\begin{array}{l}\text { Cronbach } \\
\text { values }\end{array} & \text { Alpha } \\
\end{array}$ \\
\hline \multirow{4}{*}{ Conversations } & Ch1 & 0.852 & \multirow{4}{*}{0.819} & \multirow{4}{*}{0.884} \\
\hline & Ch2 & 0.897 & & \\
\hline & Ch3 & 0.869 & & \\
\hline & Ch4 & 0.831 & & \\
\hline \multirow[t]{4}{*}{ Groups } & Gr1 & 0.821 & \multirow{4}{*}{0.747} & \multirow{4}{*}{0.851} \\
\hline & Gr2 & 0.861 & & \\
\hline & Gr3 & 0.786 & & \\
\hline & $\mathrm{Gr} 4$ & 0.867 & & \\
\hline \multirow[t]{5}{*}{ Participation } & Sh1 & 0.780 & \multirow{5}{*}{0.815} & \multirow{5}{*}{0.856} \\
\hline & Sh2 & 0.883 & & \\
\hline & Sh3 & 0.812 & & \\
\hline & Sh4 & 0.782 & & \\
\hline & Sh5 & 0.746 & & \\
\hline \multirow[t]{4}{*}{ Relations } & Re1 & 0.712 & \multirow{4}{*}{0.787} & \multirow{4}{*}{0.880} \\
\hline & Re2 & 0.871 & & \\
\hline & Re3 & 0.909 & & \\
\hline & Re4 & 0.941 & & \\
\hline \multirow{5}{*}{$\begin{array}{l}\text { Promote small } \\
\text { projects products }\end{array}$} & PPP1 & 0.802 & \multirow{5}{*}{0.876} & \multirow{5}{*}{0.919} \\
\hline & PPP2 & 0.890 & & \\
\hline & PPP3 & 0.883 & & \\
\hline & PPP4 & 0.901 & & \\
\hline & PPP5 & 0.867 & & \\
\hline
\end{tabular}

\section{Analysis of Study Data and Results}

\subsection{Descriptive Statistics of the Study Variables}

Table 3. Descriptive statistics of the study variables

\begin{tabular}{|l|c|c|c|c|}
\hline \multicolumn{1}{|c|}{ variable Mean } & $\begin{array}{c}\text { standard } \\
\text { deviation }\end{array}$ & Maximum value & Minimum value \\
\hline Conversations & 3.65 & 0.80 & 5.00 & 1.25 \\
\hline Groups & 3.54 & 0.88 & 5.00 & 1.25 \\
\hline Participation & 3.70 & 0.76 & 5.00 & 1.60 \\
\hline Relations projects & 3.63 & 0.86 & 5.00 & 1.50 \\
\hline $\begin{array}{l}\text { Promote small } \\
\text { products }\end{array}$ & 3.55 & 0.86 & 5.00 & 1.00 \\
\hline
\end{tabular}

We note in Table (3) that the descriptive statistics of the study variables, where the mean ranged from (3.54-3.70) and the variable (participation) was the largest in terms of the arithmetic mean as it reached (3.70) with a standard deviation (0.76) and the variable (groups) was the least in terms of The arithmetic mean, as it reached (3.54), with a standard deviation (0.88).

\subsection{The Normal Distribution Test}

The stipulation of the normal distribution of the data is one of the most basic conditions for conducting 
parametric tests and testing hypotheses through simple and multiple linear regressions (Hair et al., 2010). The researcher conducted a normal distribution test through the torsion coefficient and the Kurtosis coefficient, where the value of the torsion coefficient should be less than (1) and the Kurtosis coefficient less than (3) and Table (4) shows these values which show that the torsion coefficient was its value for all variables less than (1) And that the coefficient of flocculation was less than (3).

Table 4. The normal distribution test for the study variables

\begin{tabular}{|l|l|l|}
\hline \multicolumn{1}{|c|}{ Variable } & Skewness Coefficient & Kurtosis coefficient \\
\hline Conversations & -0.570 & 0.465 \\
\hline Groups & -0.134 & -0.532 \\
\hline Participation & -0.404 & 0.084 \\
\hline Relations & -0.493 & -0.132 \\
\hline Promote small projects products & -0.643 & 0.391 \\
\hline
\end{tabular}

\subsection{Multicollinearity Test}

Before testing the hypotheses, the researcher made sure that the independent variables were free of large correlations between them, which may lead to problems in estimating the regression model in terms of providing false regression results, as this condition was tested through the VIF and permittivity inflation factor, where the value of VIF must be less than (10) The permittivity value is greater than (0.10), and it can be seen from Table (5) that the values of VIF ranged from (2.469-4.304) and the permittivity values were (0.405-0.232). Therefore, the independent variables are not closely related, which may lead to the problem of false regression.

Table 5. Multicollinearity test between independent variables

\begin{tabular}{|l|l|l|}
\hline variable & VIF & Tolerance \\
\hline Conversations & 4.304 & 0.232 \\
\hline Groups & 2.843 & 0.352 \\
\hline Participation & 2.469 & 0.405 \\
\hline Relations & 3.102 & 0.322 \\
\hline
\end{tabular}

\subsection{Interconnection Matrix (Pearson)}

Table 6. Matrix of interrelationships between study variables

\begin{tabular}{|l|l|l|l|l|l|}
\hline & conversations & Groups & Participation & relations & promotion \\
\hline Conversations & 1 & & & & \\
\hline Groups & $0.779 * *$ & 1 & & & \\
\hline Participation & $0.700 * *$ & $0.682 * *$ & 1 & & \\
\hline relations & $0.795 * *$ & $0.617 * *$ & $0.701 * *$ & 1 & \\
\hline promotion & $0.780 * *$ & $0.610^{* *}$ & $0.642 * *$ & $0.860 * *$ & 1 \\
\hline
\end{tabular}

** A function at the level of statistical significance (0.01)

Table (6) shows the matrix of inter-correlations between the variables of the study, as it is clear that all the relationships between the variables are moderate to strong and all are positive, as they ranged from (0.610-0.860). As for the relationship between groups and the promotion of small projects, it reached (0.610), and by looking at the previous matrix, it becomes clear that the correlation coefficients are good and therefore the simple and multiple linear regression tests is valid for this study. 


\subsection{Test the Hypotheses of the Study}

In order to analyze the data and testing research hypotheses, simple regression and multiple regressions will be used as follows:

Ho1: "There is no statistically significant effect at a significance level of $(\alpha \leq 0.05)$ (the dimensions of social media sites (conversations, participation, groups, and relationships) in promoting the products of small enterprises in the State of Kuwait."

Table 7. The results of the hypothesis test of the first main study

\begin{tabular}{|l|l|l|l|l|l|l|l|}
\hline variable & $\begin{array}{l}\text { Correlation } \\
\text { coefficient R }\end{array}$ & $\begin{array}{l}\text { Determination } \\
\text { coefficient R2 }\end{array}$ & F value & $\begin{array}{l}\text { Significance } \\
\text { level }\end{array}$ & $\beta$ & Calculated T & $\begin{array}{l}\text { Significance } \\
\text { level }\end{array}$ \\
\hline $\begin{array}{l}\text { Social } \\
\text { Media }\end{array}$ & 0.813 & 0.660 & 400.313 & 0.000 & 0.955 & 20.008 & 0.000 \\
\hline
\end{tabular}

It is evident from the previous table the simple linear regression test to test the hypothesis of the first main study, as it is evident through the value of the correlation coefficient $(0.813)$ that there is a strong relationship between the two variables and the value of the coefficient of determination R2 (0.660) means that the change in the promotion of the products of small enterprises due to Social networking sites had a value of (66\%) and the value of $F$ was (400.313) and its probability value (0.000) and the value of the regression coefficient was beta (0.955). This value indicates that the relationship between the two variables is strong and positive, and the calculated $t$ value was (20.008), meaning it is greater than The tabular value, which is equal to (1.96) and the probability value (0.000), i.e. it is smaller than the level of statistical significance at (0.05). Therefore, the null hypothesis was rejected and the alternative hypothesis was accepted with the existence of a statistically significant effect of social media on promoting the products of small enterprises in the State of Kuwait.

In order to test the hypotheses of the sub-study, the results of the multiple linear regression tests were as follows:

Table 8. Results of the sub-study hypothesis test

\begin{tabular}{|c|c|c|c|c|c|c|c|}
\hline variable & $\begin{array}{l}\text { Correlation } \\
\text { coefficient R }\end{array}$ & $\begin{array}{l}\text { Determination } \\
\text { coefficient R2 }\end{array}$ & $\mathrm{T}$ Value & $\begin{array}{l}\text { Significance } \\
\text { level }\end{array}$ & B & $\begin{array}{c}\text { Calculated } \\
\qquad \mathrm{T}\end{array}$ & $\begin{array}{c}\text { Significance } \\
\text { level }\end{array}$ \\
\hline Conversations & \multirow{4}{*}{0.875} & \multirow{4}{*}{0.766} & \multirow{4}{*}{166.211} & \multirow{4}{*}{0.000} & 0.280 & 3.705 & 0.000 \\
\hline Participations & & & & & 0.022 & 0.389 & 0.698 \\
\hline Groups & & & & & -0.048 & -0.792 & 0.430 \\
\hline Relations & & & & & 0.671 & 11.186 & 0.000 \\
\hline
\end{tabular}

The previous table shows the multiple linear regression test to test the sub-study hypotheses, as it is clear that the value of the multiple correlation coefficient was $(0.875)$ and this value indicates that there is a strong relationship between the independent variables and the dependent variable and the value of the coefficient of determination was (0.766), meaning that the independent variables combined may I interpreted an amount $(76.6 \%)$ of the variance in the dependent variable and the calculated value of $\mathrm{F}$ was (166.211) and its probability value was (0.000). This value indicates the significance and significance of the regression model. (0.280) and the calculated $\mathrm{t}$ value was $(3.705)$, the probability value $(0.000)$, the variable relationships $(0.671)$, the calculated t value (11.186), and the probability value (0.000), meaning that the effect of conversation and relationships on promoting the products of small projects is statistically significant at the statistical significance questioner ( As for the two participating variables and groups, they did not have a statistically significant effect on promoting the products of small enterprises, as the beta values were $(0.022),(-048)$ and the calculated t values were $(0.389)$, $(-0.792)$ and the probability values were $(0.698),(0.430)$. Therefore, there is no statistically significant effect of participation and groups on promoting the products of small enterprises in the State of Kuwait.

The researcher conducted a test of the study hypotheses according to demographic variables, where the gender and years of experience were chosen to know the effect of social media benefits on promoting the products of small enterprises in the State of Kuwait as follows: 
Ho2: "There is no statistically significant effect at a level of significance $(\alpha \leq 0.05)$ for the dimensions of social media sites (conversations, participation, groups, relationships) in promoting the products of small enterprises in the State of Kuwait according to the different gender".

Table 9. The results of the hypothesis test of the second main study

\begin{tabular}{|l|l|l|l|l|c|c|c|}
\hline variable & $\begin{array}{l}\text { Correlation } \\
\text { coefficient } \\
\text { R }\end{array}$ & $\begin{array}{l}\text { Determination } \\
\text { coefficient R2 }\end{array}$ & F Value & $\begin{array}{l}\text { Significance } \\
\text { level }\end{array}$ & $\boldsymbol{\beta}$ & $\begin{array}{c}\text { Calculated } \\
\mathrm{T}\end{array}$ & $\begin{array}{c}\text { Significance } \\
\text { level }\end{array}$ \\
\hline \multicolumn{7}{|c|}{ Male Group } \\
\hline $\begin{array}{l}\text { Social } \\
\text { Media }\end{array}$ & 0.750 & 0.563 & 207.438 & 0.000 & 0.750 & 14.403 & 0.000 \\
\hline $\begin{array}{l}\text { Social } \\
\text { Media }\end{array}$ & 0.901 & 0.812 & 186.020 & 0.000 & 0.901 & 13.639 & 0.000 \\
\hline
\end{tabular}

The previous table shows the simple linear regression test for comparison between the two groups of males and females, as it is clear that the correlation coefficient in the male group was $(0.750)$ and in the female group (0.901) and the value of the determination coefficient in the male group was (0.563) and in the female group (0.812). The explanation of the effect of social networking sites on promoting the products of small enterprises according to the female group is better than the interpretation of the effect of social media sites on promoting the products of small enterprises according to the group of males, since the group of females interpreted $(81.2 \%)$ of the change in the dependent variable while the group of males (56.3\%) of the change in the dependent variable, and the value of $\mathrm{F}$ computed in the male group was (207.438) and (186.020) in the female group and the probability value for both groups was $(0.000)$ and the value of the beta regression coefficient for the variable social media according to the group of males (0.750 The value of the calculated t was (14.403) and the probability value was $(0.000)$, while the value of the beta regression coefficient for the female group was $(0.901)$ and the calculated t value was (13.639) and the probability value was (0.000). For me, if the null hypothesis is rejected and the alternative hypothesis is accepted, which states that there is a statistically significant effect of social media on promoting the products of small enterprises in the State of Kuwait according to the difference of gender and for the benefit of females, as the value of the beta regression coefficient in the female group is better than the beta regression coefficient value in a males group.

Ho3: "There is no statistically significant effect at a level of significance $(\alpha \leq 0.05)$ for the dimensions of social media sites (conversations, participation, groups, relationships) in promoting the products of small enterprises in the State of Kuwait according to the difference in academic qualifications.

Table 10. The results of the hypothesis test of the third main study

\begin{tabular}{|c|c|c|c|c|c|c|c|}
\hline variable & $\begin{array}{c}\text { Correlation } \\
\text { coefficient } \\
\text { R }\end{array}$ & $\begin{array}{l}\text { Determination } \\
\text { coefficient R2 }\end{array}$ & F Value & $\begin{array}{c}\text { Significance } \\
\text { level }\end{array}$ & $\beta$ & $\begin{array}{c}\text { Calculated } \\
\mathrm{T}\end{array}$ & $\begin{array}{c}\text { Significance } \\
\text { level }\end{array}$ \\
\hline \multicolumn{8}{|c|}{ General Secondary Group and less } \\
\hline variable & 0.678 & 0.459 & 43.342 & 0.000 & 0.678 & 6.583 & 0.000 \\
\hline \multicolumn{8}{|c|}{ Bachelor's degree group } \\
\hline $\begin{array}{l}\text { Social } \\
\text { Media }\end{array}$ & 0.883 & 0.779 & 419.057 & 0.000 & 0.883 & 20.471 & 0.000 \\
\hline \multicolumn{8}{|c|}{ Postgraduate group } \\
\hline $\begin{array}{l}\text { Social } \\
\text { Media }\end{array}$ & 0.600 & 0.360 & 18.32 & 0.000 & 0.600 & 4.246 & 0.000 \\
\hline
\end{tabular}

The previous table shows the simple linear regression test to find out the effect of social media on promoting the products of small enterprises in the State of Kuwait according to scientific qualification, and it is clear from the previous table that the correlation coefficient in the high school group or less has reached (0.678), the Bachelor group (0.883) and the group of studies. These values indicate the existence of a strong relationship between the two variables in all the previous groups. The value of the determination coefficient for the high school group or less was (0.459) For the bachelor group (0.779) and for the postgraduate group (0.360), it is evident that the explanatory power of the effect of social media on promoting the products of small enterprises in the State of Kuwait was for the bachelor group, as the explanatory strength reached (77.9\%) and then for the secondary 
group and less (45.9\%) and the group of studies The higher (36\%) and all $\mathrm{F}$ values were statistically significant and had a probability value (0.000). As for the beta regression coefficients, they were for the high school group or less (0.678) for the undergraduate group (0.883) and for the postgraduate group (0.600), and all the calculated $\mathrm{t}$ values were greater than (1.96) for the high school group or less $(6,583)$, for the bachelor's group $(20,471)$, and for the graduate studies group $(4,246)$, and all the probability values were $(0.000)$. Therefore, the null hypothesis is rejected and the alternative hypothesis is accepted with the existence of a statistically significant impact of social media on promoting the products of small enterprises In the State of Kuwait, for the benefit of the most influential bachelor's group, then high school or less, and then postgraduate studies.

\section{Conclusions of the Study}

This study aimed to study the impact of social networking sites in its dimensions (conversations, participation, groups, relationships) on promoting the products of small enterprises in the State of Kuwait and also to study the effect of social media sites in their dimensions (conversations, participation, groups, relationships) on promoting small enterprise products in the State of Kuwait According to the difference in gender and also scientific qualification, the results of the descriptive statistics were average, as the arithmetic mean was the highest for the participation variable as it reached (3.70). This indicates that the respondents to the study tool believe that their most use of social media was in sharing with others. (3.54) the results of the study showed that there were correlations between all the variables of the study, and all the relationships were statistically significant at a significance level less than (0.01). It was found through the results of the statistical analysis and the analysis of the study data that there is a statistically significant effect of social media sites on promoting the products of small enterprises in the State of Kuwait through a simple linear regression test. This result indicates that social media sites affect the way Positive and noticeable in the process of promoting small projects 'products, as small companies try to reduce advertising costs and the large capital costs associated with that by resorting to social media and thus improving the promotion of small enterprises' products in Kuwait. The results of the study confirmed the existence of an impact of each of the dimensions of social networking sites (talks, Relationships) to promote small business products in Kuwait where talks lead Personal and collective to improve the reputation of small companies in a way that leads to customer confidence in these products and also strengthens relationships from promoting goods because relationships are based on trust and experience, and therefore better promotion of these products will be made. The study confirmed that there is no effect for each of (groups, participation) on promoting the products of small enterprises. The study also revealed that there is an impact of social media on promoting the products of small enterprises in Kuwait according to the difference of gender. The effect of this was for the group of females more than males, where the value of the coefficient of determination for the female group was (0.812) and the value of the coefficient of determination for the male group was (0.563). Therefore, the female group's interpretation of the effect was greater than the male group. As the result indicates that Kuwait is an Arab country characterized by masculinity and therefore most of the small projects are managed through the home. Thus, the beneficiaries of these products will be females, and the study also showed that social media has an impact on promoting the products of small enterprises in Kuwait, according to the different scientific qualifications. Where the (Bachelor's) group were the most influential, where the determination coefficient for this group was (0.779), then a general secondary group or less (0.459), and then postgraduate studies $(0.360)$.

\section{Recommendations}

First: Recommending the importance of small and medium companies adopting social media in their activities, especially in marketing and promotion activities

Second: Recommending focusing on the efforts of companies with small projects to increase the effectiveness of their content on social media.

Third: The necessity to form working groups specialized in social media in these projects to improve the effectiveness of promoting their products.

Fourth: Increasing interest in the credibility of information published about products through social media to improve customers' sense of the reliability of social media as a method of online marketing and selling.

Fifth: Inviting researchers to study social networking sites and their impact on other marketing activities such as pricing, selling, marketing confidence, and customer loyalty and satisfaction.

\section{References}

Akpan, S. (2016). The Influence of Cultural Factors on Consumer Buying Behavior (A Case Study of PORK). British Journal of Marketing Studies, 4(6), 44-57. 
Al-Dabsi, A. K., \& Chefs, Z. (2013). The role of social media in shaping public opinion among Jordanian university students. Journal of Humanities and Social Sciences Studies, 40(1), 66-81.

Al-Najjar, F., Al-Najjar, N., \& Al-Zoubi, M. (2013). Scientific Research Methods: An Applied Perspective. Dar Al-Hamid for Publishing and Distribution, Amman, Jordan.

Al-Nsour, H., Al-Manasrah, A., \& Ziadat, M. (2016). The Impact of Marketing Using Social Media on the Intention to Buy in Jordan. Jordanian Journal of Business Administration, 12(3), 519-530. https://doi.org/10.12816/0033321

Al-Shibli, O. (2014). Factors affecting adoption and purchase intent using social media as a marketing tool. unpublished $\mathrm{PhD}$ thesis, University of Islamic Sciences, Amman, Jordan.

Barber, N., \& Scarcelli, J. M. (2009). Clean restrooms: how important are they to restaurant Consumers? Journal of Food Service, 20(6), 309-320. https://doi.org/10.1111/j.1748-0159.2009.00155.x

Bishmaf, M. (2016). The impact of social media marketing on the intention to purchase: Understanding the Mark as a Modified Variable. Unpublished Master Thesis, Applied Sciences University, Amman, Jordan.

Boyd, D. (2007). Social Network Sites: Definition, History, and Scholarship. Computer Mediated Communication, 3-20. https://doi.org/10.1111/j.1083-6101.2007.00393.x

Cheng, C., Lin, S., \& Tsai, C. (2014). Investigating Consumer Preferences in Choosing Vegetarian Restaurants Using Conjoint Analysis. Current Urban Studies, 2(3), 279. https://doi.org/10.4236/cus.2014.23026

Coursaris, C., \& Van Osch, W. (2016). Exploring the Effects of Source Credibility on Information Adoption on YouTube. International Conference on HCI in Business, Government and Organizations, Springer International Publishing, USA, 16-25. https://doi.org/10.1007/978-3-319-39396-4_2

Dou, X., Walden, J., Lee, S., \& Lee, J. (2012). Does source matter? Examining source effects in online product reviews. Computers in Human Behavior, 28(5), 1555-1563. https://doi.org/10.1016/j.chb.2012.03.015

Ehsan, U. (2012). Factors important for the selection of fast food restaurants: an empirical study across three cities of Pakistan. British Food Journal, 114(9), 1251-1264. https://doi.org/10.1108/00070701211258808

El-Sayed, A., \& Abdel-Al, H. (2009). Social Networks and their Impact on the Specialist and Library: A Comprehensive Study of Presence and Use of Facebook. The Thirteenth Conference of Libraries and Information Professionals, Cairo, Egypt.

Facebook. (2004, 2 4). Facebook Inc. Retrieved December 5, 2010, from http://www.face.com

Fulcher, C. (2014). Community commons: A unifying public good website for healthy, sustainable, and livable communities. National Civic Review, 103(1), 912. https://doi.org/10.1002/ncr.21165

Goyal, M. (2016). A study of impact of social media on consumer behavior in restaurant industry of Jaipur city. International Journal of Advance Research and Innovative Ideas in Education, 2(3), 2435-2441.

Hamdan, A. (2016). The impact of social media on the electronic purchasing decision process in the fashion sector. unpublished Master Thesis, Applied Sciences University, Amman, Jordan.

Hu, X. (2015). Assessing Source Credibility On Social Media-An Electronic WordOf-Mouth Communication Perspective. Unpublished PHD Dissertation, Bowling Green State University, USA.

Jasra, M. (2010, November 24). The History of Social Media [Infographic]. Retrieved December 4, 2010, from http://www.webanalyticsworld.net/2010/11/history-ofsocial-media-infographic.html

Kabadayi, S., \& Price, K. (2014). Consumer-brand engagement on Facebook: liking and commenting behaviors. Journal of Research in Interactive Marketing, 8(3), 203-223. https://doi.org/10.1108/JRIM-12-2013-0081

Lafferty, B., \& Goldsmith, R. (1999). Corporate credibility's role in consumers' attitudes and purchase intentions when a high versus a low credibility endorser is used in the ad. Journal of business research, 44(2), 109-116. https://doi.org/10.1016/S0148-2963(98)00002-2

Manning, J. (2014). Social media, definition and classes of In K. Harvey (Ed Encyclopedia of social media and politics (pp. 1158-1162). Thousand Oaks, CA: Sage.

Mohan Raj, P., \& Ananth, S. (2016). Brand Preferences of Newspapers- Factor Analysis Approach. Research Journal of Economics and Business Studies, 5(11), 17-26.

Obaidat, M., \& Al-Ghadeer, H. (2011). The effect of the elements of the marketing mix on Jordanian pharmacists' preference for the local drug compared to its foreign counterpart. Administrative Sciences 
Studies, 38(1), 180-198.

Parveen, F., Jaafar, N., \& Sulaiman, A. (2015). Role of Social Media on Information Accessibility. PACIS, 8(4), 237-253.

Tang, L., \& Liu, H. (2010). Understanding group structures and properties in social media. Link Mining: Models, Algorithms, and Applications, 51(4) 83-491.

TIMES, L. (2010). The business and culture of our digital lives. Los Angeles Times, 1.

\section{Copyrights}

Copyright for this article is retained by the author(s), with first publication rights granted to the journal.

This is an open-access article distributed under the terms and conditions of the Creative Commons Attribution license (http://creativecommons.org/licenses/by/4.0/). 